\title{
Impaired PRR expression modulates inflammation-triggered oxidative stress and pathogenesis of recurrent vulvovaginal infections
}

\author{
Namarta Kalia ${ }^{1}$, Manpreet Kaur ${ }^{2 *}$, Sujata Sharma ${ }^{3}$ and Jatinder Singh ${ }^{1 *}$
}

\begin{abstract}
Introduction: Both inflammation and oxidative stress (OS) stimulate each other and act together in providing defense against recurrent vulvovaginal infections (RVI). Both processes are in such a tight link, that defect in one may lead to defect in other; therefore, recognition and treatment of primary anomaly are of great clinical importance.

Objective: To investigate the relationship between PRRs, i.e., mannose-binding lectin (MBL) and dendritic cell-associated C-type lectin-1 (Dectin-1) and oxidative stress parameters, i.e., total antioxidant status (TAC), total oxidant status (TOS), and oxidative stress index (OSI), along with their dependency on system factors in modulating susceptibility to RWI.

Study design: This case-control study included 258 RWI cases and 203 age-matched controls. TAC, TOS, and OSI were determined according to modified standard protocols. MBL and Dectin-1 levels were assessed by commercially available kits.

Results: RWI and bacterial vaginosis showed significantly low TAC than controls. Significantly low TOS was observed in cases than controls. RWI and vulvovaginal candidiasis showed significantly low OSI than controls. Significantly low MBL and high Dectin-1 levels were observed in cases than controls. Significant, but unexpected weak relationship, was observed between OS parameters and PRRs. Serum biomarkers were found to be dependent on confounding variables.

Conclusion: Low MBL levels were found to be the primary source of defect in the present study that leads to the dysregulated immune system with no observed protective oxidative stress, increasing susceptibility to RWI. Therefore, substituting the required MBL in representative Indian population may restore host homeostasis and provide recovery from RWI.
\end{abstract}

Keywords: ABTS, Anti-oxidative stress, Correlation, Regression, ELISA, Random capillary blood glucose, Infectious diseases

\section{Introduction}

The human vaginal microbiome is normally populated by many potentially dangerous bacterial and fungal species, overgrowth of which can lead to vulvovaginal infections (VVI) (Li et al., 2012a). The common VVI includes bacterial vaginosis (BV), vulvovaginal candidiasis (VVC), and trichomoniasis (Mulu et al., 2015). However, the

\footnotetext{
* Correspondence: dr.manpreetdhuna@gmail.com;

jatinderarora2009@gmail.com

${ }^{2}$ Department of Human Genetics, Guru Nanak Dev University, Amritsar,

Punjab, India

${ }^{1}$ Department of Molecular Biology and Biochemistry, Guru Nanak Dev

University, Amritsar, Punjab, India

Full list of author information is available at the end of the article
}

repeated occurrences of common VVI, referred as recurrent VVI (RVVI), are the researcher's main issue (Powell \& Nyirjesy, 2014). An abnormal vaginal discharge is the characteristic and commonly complained symptom of RVVI (Workowski \& Bolan, 2015). National Family Health Survey 2 reported 30 percent prevalence of vaginal discharge in India with $29.9 \%$ prevalence in Delhi (National Family Health Survey 2 (NFHS 2) 1998-99, India, 1999). Adverse pregnancy-related complications and advance co-morbid conditions are the serious outcomes of untreated RVVI (Atashili et al., 2008; Durugbo et al., 2015; Rose et al., 2017). Uncontrolled diabetes, unchecked use of antibiotics, black race, poor personal 
hygiene, use of birth control options, hormonal imbalance, sexual activity, and immunosuppression are the other suggested predisposing factors of RVVI (Gonçalves et al., 2016). However, women without any known predisposing factors have been documented to acquire RVVI, suggesting a fine interplay between host defense system and vaginal microbiota that determines the disease outcome (Bradford et al., 2013). Therefore, to get an accurate definition of vaginal health and infections, exploration of host defense system active in the removal of RVVI pathogens is necessary.

Inflammation is a fine mechanism of host immune system that is meant to eliminate pathogens. This process involves pattern recognition receptors (PRRs) activation by pathogen-associated molecular patterns (PAMPs) that further induce downstream signaling pathways and subsequent release of inflammatory immune mediators, with the aim of pathogens killing by effector phagocytic cells (Medzhitov, 2008). All these inflammatory stages generate reactive oxidants as an essential part of defense mechanism, leading to a state of oxidative stress (Lugrin et al., 2014). Oxidative stress is a disproportionate state, generated due to an excess of oxidants production than anti-oxidants, with considerable biological consequences and thus contributes to the pathophysiology of disease. The first class of reactive oxidants includes reactive oxygen species (ROS), generated by the action of enzyme nicotinamide adenine dinucleotide phosphate (NADPH) oxidase (NOX) and include superoxide anion radical $\left(\mathrm{O}_{2}{ }^{-}\right)$, hydrogen peroxide $\left(\mathrm{H}_{2} \mathrm{O}_{2}\right)$, and the hydroxyl radical $\left(\mathrm{OH}^{*}\right)$ (Jomova et al., 2010). The second class of reactive oxidants includes reactive nitrogen species (RNS), generated by the action of enzyme NO synthase (NOS) and include nitrogen oxide free radical (NO), the parent molecule of all RNS (Pacher et al., 2007). The NOS exist in three different isoforms, in which neuronal NOS (nNOS) and endothelial NOS (eNOS) express constitutively, while inducible NOS (iNOS) express only upon stimulation by pathogen, PAMPs. and by pro-inflammatory cytokines (Förstermann \& Sessa, 2011).

Human mannose-binding lectin (MBL) and dendritic cell-associated C-type lectin-1 (Dectin-1) are the two prototypical PRRs of innate immunity, whose direct role in defense against RVVI pathogens has been defined (Ip \& Lau, 2004; Pellis et al., 2005; Ferwerda et al., 2009; Li et al., 2012b). Moreover, our studies along with others have suggested the involvement of these PRRs in determining RVVI susceptibility (Ferwerda et al., 2009; Babula et al., 2003; Liu et al., 2006; Milanese et al., 2008; Henić et al., 2010; Ghazanfari et al., 2017; Kalia et al., 2017, 2018, 2019a, 2019b). In addition, both MBL and Dectin1 have been shown to mediate ROS release as a part of defense mechanism against pathogens (Li et al., 2012b;
Underhill et al., 2005; Kalia et al., 2016; Lima-Junior et al., 2017). These oxidants further lead to PRRs activation that subsequently results in both oxidative and nitroxidative stress after multiple rounds of magnification, which ultimately leads to chronic inflammatory response (Lucas \& Maes, 2013). The pathological increase of ROS generation has been recognized in RVVI that plays an important role in maintaining low burden of infection (Babula et al., 2005; Malla et al., 2004; Yadav et al., 2006; de Souza Bonfim-Mendonça P, Ratti BA, Godoy JD, 2014; Chen et al., 2015).

From this background, we sought to investigate the relationship between PRRs and oxidative stress parameters along with their dependency on system factors in modulating susceptibility to RVVI, making the present study first approach towards it.

\section{Material and methods \\ Participants}

Two hundred and fifty eight pre-diagnosed RVVI (mean age \pm SD, $29.33 \pm 8.32$ years) cases, with minimum 4 documented recurrent experiences in a year, as per recommendation by gynecologist, were recruited from Department of Obstetrics and Gynaecology, Bebe Nanki Mother and Child Care Centre, Government Medical College, Amritsar $(\mathrm{Pb})$. These cases complained of having frequent symptoms like itching, burning, pelvic pain, vaginal fishy smell, and discharge. Two hundred and three age-matched healthy women (mean age \pm SD, $29.33 \pm 8.17$ years) without any recurrent vaginal infection complaints were used as controls. Participants with HIV infections or any other chronic conditions, under chemotherapy and using immunosuppressive medications were excluded from the study.

\section{Clinical samples and RVVI categories}

Serum was separated from the peripheral blood that was collected from RVVI cases $(n=258)$ as well as healthy controls $(n=203)$. For this, the blood samples collected in the plain vials were incubated at $37{ }^{\circ} \mathrm{C}$ and centrifuged (REMI, India) at $600 \times g$ for $30 \mathrm{~min}$. Serum was obtained as transparent pale shiny supernatant that was transferred to fresh vials. From this, the further aliquots were prepared and stored at $-80{ }^{\circ} \mathrm{C}$ (Skadi ${ }^{\circ}$ Green Line, Saudi Arabia), pending further use. Vaginal discharge samples from RVVI cases $(n=200)$ were processed on the basis of standard diagnostics methods specified in European (IUSTI/WHO) guidelines on vaginal discharge management (Sherrard et al., 2011). These details have been reported previously, which categorized these RVVI cases into three main groups, i.e., bacterial vaginosis (BV; $n=97)$, Vulvovaginal candidiasis (VVC; $n=62)$, and mixed infections (MI; $n=41$ ), i.e., cases with both BV and VVC (Kalia et al., 2015). However, 58 RVVI 
cases could not be processed for RVVI categories, as some participants were menstruating and others were not willing to give vaginal samples.

\section{Confounding parameters}

The confounding parameters include participant's age, age of initiation of sexual activity, duration of infection, and random capillary blood glucose (RCBG) (Table 1). Of these variables, RCBG for each participant was determined using glucometer (Glucosign, South Korea) according to the manufacturer's instructions (Somannavar et al., 2009; Shewade et al., 2017). The information regarding the rest of the continuous variables was obtained from proforma filled for each participant during sampling. The proforma also included details regarding obstetric history, menstrual history, and clinical characteristics; however, the information regarding this has already been reported previously (Kalia et al., 2017, 2018, 2015).

\section{Total antioxidant capacity}

Serum TAC (sTAC) was measured using a method developed by Erel (Erel, 2004) with slight modifications using the microplate method (Gupta et al., 2009). The theory involves the reduction of blue-green colored complex 2,2'-azinobis (3-ethylbenzothiazoline-6-sulfonate) cations $\left(\mathrm{ABTS}^{+}\right)$to its original colorless reduced form (ABTS). This occurs in the presence of any matter that can be oxidized, e.g., anti-oxidants. Hence, the rate of reduction is directly proportional to the amount of anti-oxidants in samples.

Briefly, $5 \mu \mathrm{l}$ of each serum sample was added in triplicates to the wells of the flat bottom microplate (Tarson, India), along with blank and standard. Then, $200 \mu \mathrm{l}$ of reagent I was added to each well and absorbance was taken at 655 $\mathrm{nm}$ on a microplate reader (BIO-RAD, iMark ${ }^{\mathrm{Tm}}$, USA). Afterward, $20 \mu \mathrm{l}$ of reagent II was added to wells and incubated at $37^{\circ} \mathrm{C}$ for $5 \mathrm{~min}$ before taking absorbance. Final absorbance was read at $655 \mathrm{~nm}$. The difference in absorbance at $655 \mathrm{~nm}$ was used for calculating TAC. Phosphatebuffered saline (PBS) (0.01 M, pH7.2) was used as blank. The assay was calibrated using Trolox as standard. The standard curve was obtained from different concentration of Trolox $(0.25,0.50,0.75$, and $1.00 \mathrm{mmol}$ Trolox
equivalent/L), and the results were expressed in millimoles Trolox equivalent per liter (mmol Trolox equiv/L).

\section{Total oxidant status}

Serum TOS (sTOS) was measured using a method developed by Erel (Erel, 2005) with slight modifications using the microplate method (Gupta et al., 2009). The theory involves the oxidation of ferrous ion $\left(\mathrm{Fe}^{2+}\right)$ to its oxidized form ferric ion $\left(\mathrm{Fe}^{3+}\right)$. The ferric ions react with xylenol orange to form colored complex. This occurs in the presence of any matter that can be reduced, e.g., various oxidant species. Thus, the rate of oxidation is directly proportional to the amount of oxidants present in the samples and hence color production.

Briefly, $35 \mu \mathrm{l}$ of each serum sample was added in triplicates to the wells of the flat bottom microplate (Tarson, India), along with blank and standard. Then, $225 \mu \mathrm{l}$ of reagent I was added to each well and absorbance was taken at $595 \mathrm{~nm}$ on microplate reader (BIO-RAD, $\mathrm{iMark}^{\mathrm{Tw}}$, USA). Afterward, $11 \mu \mathrm{l}$ of reagent II was added to wells and incubated at $37{ }^{\circ} \mathrm{C}$ for 5 min before taking absorbance. Final absorbance was read at $595 \mathrm{~nm}$. The difference in the absorbance at $595 \mathrm{~nm}$ was used for calculating TOS. PBS (0.01 M, pH7.2) was used as blank. The assay was calibrated using $\mathrm{H}_{2} \mathrm{O}_{2}$ as standard. The standard curve was obtained from different concentration of $\mathrm{H}_{2} \mathrm{O}_{2}(25,50,75,100,125,150,175$, and 200 $\mu \mathrm{mol} \mathrm{H}_{2} \mathrm{O}_{2}$ equivalent/L), and the results were expressed in terms of micromole $\mathrm{H}_{2} \mathrm{O}_{2}$ equivalent per liter $(\mu \mathrm{mol}$ $\mathrm{H}_{2} \mathrm{O}_{2}$ Equiv/L).

\section{Oxidative stress index}

Serum oxidative stress index (sOSI) was calculated by ratio of TOS to TAC (Aycicek et al., 2005; Harma et al., 2005), i.e.,

$$
\text { OSI }=\frac{\operatorname{TOS}\left(\mu \mathrm{mol} \mathrm{H}_{2} \mathrm{O} \text { Equiv } / \mathrm{L}\right)}{\mathrm{TAC}(\mu \mathrm{mol} \text { Trolox Equiv } / \mathrm{L})}
$$

\section{MBL and Dectin-1}

Enzyme-linked immunosorbent assay (ELISA) was used, for the quantification of serum MBL (sMBL) and serum Dectin-1 (sDectin-1 levels), using commercially

Table 1 Confounding parameters of study populations

\begin{tabular}{|c|c|c|c|c|c|}
\hline Confounding variables & $\begin{array}{l}\mathrm{HC} \\
(n=203)\end{array}$ & $\begin{array}{l}W l \\
(n=258)\end{array}$ & $\begin{array}{l}\text { BV } \\
(n=97)\end{array}$ & $\begin{array}{l}\text { WC } \\
(n=62)\end{array}$ & $\begin{array}{l}\mathrm{Ml} \\
(n=41)\end{array}$ \\
\hline Age (years) & $29.33 \pm 8.17$ & $29.33 \pm 8.32$ & $30.53 \pm 9.09$ & $29.45 \pm 8.06$ & $26.48 \pm 5.07$ \\
\hline Age of initiation of sexual activity (years) & $23.02 \pm 4.12$ & $20.94 \pm 3.69$ & $21.37 \pm 3.97$ & $20.96 \pm 3.90$ & $20.56 \pm 2.47$ \\
\hline Random capillary blood glucose (RCBG, mg/dl) & $105.01 \pm 11.85$ & $115.80 \pm 40.31$ & $112.62 \pm 21.8$ & $116.67 \pm 46.24$ & $120.85 \pm 63.17$ \\
\hline Duration of infection (years) & - & $3.32 \pm 4.24$ & $3.11 \pm 3.83$ & $3.43 \pm 4.48$ & $3.69 \pm 4.21$ \\
\hline
\end{tabular}

$H C$ healthy controls, $V V I$ vulvovaginal infections, $B V$ bacterial vaginosis, $V V C$ vulvovaginal infections, $M I$ mixed infections 
available kits (Ray Biotech, USA), according to the manufacturer's instructions, as reported previously (Kalia et al., 2017, 2018).

\section{Statistical analysis}

Variables were expressed as mean \pm SD. One-way analyses of variance (ANOVA) followed by Tukey's multiple comparison post-test were performed to compare serum biomarkers within group consisting of more than two categories. The correlation of serum biomarkers with cofounding parameters was checked by Pearson's correlation test. Multiple linear regression (MLR) analyses were also accounted and applied as mentioned in the equation given below:

$$
y=a+b_{1} x_{1}+b_{2} x_{2}+b_{n} x_{n}
$$

Where $y=$ dependent variable, $x_{1}, x_{2} \ldots x_{\mathrm{n}}=$ independent variables, $a=y$-intercept

$b_{1}=$ unstandardized regression coefficient for $x_{1}$ on $y$ eliminating effect of $x_{2}$ and $x_{n}$

$b_{2}=$ unstandardized regression coefficient for $x_{2}$ on $y$ eliminating effect of $x_{1}$ and $x_{n}$

$b_{n}=$ unstandardized regression coefficient for $x_{n}$ on $y$ eliminating effect of $x_{1}$ and $x_{2}$

Along with standardized beta-regression coefficients ( $\beta$ ) that explained the relative effects of independent variables on dependent variable and their statistical significance. All the statistical analyses were carried out by the statistical package for social sciences (SPSS) v 16.0 (SPSS Inc., Chicago, IL). $p$ values $\leq 0.05$ were considered significant.

\section{Results}

\section{Total antioxidant capacity}

sTAC were quantitatively estimated and compared between different categories of cases and controls, using linear regression equation, $y=-0.140 x+0.422, R^{2}=$ 0.816 obtained from Trolox standard curve. This standard curve was prepared using different concentrations of Trolox, followed by plotting their concentrations on $x$-axis and their respective absorbance on $y$-axis (Fig. $1 \mathrm{a})$. The sTAC in cases and controls have been presented using dot plot in Fig. 1b. RVVI $(0.711 \pm 0.4415$ mmol Trolox Equiv/L) and its subtypes BV (0.592 \pm $0.338 \mathrm{mmol}$ Trolox Equiv/L), VVC $(0.881 \pm 0.542$ mmol Trolox Equiv/L) and MI $(0.695 \pm 0.548 \mathrm{mmol}$ Trolox Equiv/L) showed low level of sTAC as compared to controls $(0.914 \pm 0.588 \mathrm{mmol}$ Trolox Equiv/L). However, this difference was significant only for RVVI and $\mathrm{BV}$ as compared to controls at $p=0.000$. Also, significantly low sTAC were observed in $\mathrm{BV}$ as compared to VVC at $p=0.003$.

\section{Total oxidant status}

sTOS were quantitatively estimated and compared between different categories of cases and controls, using linear regression equation, $y=0.008 x+0.099$ with $R^{2}=0.968$ obtained from $\mathrm{H}_{2} \mathrm{O}_{2}$ standard curve. This standard curve was prepared using different concentrations of standard $\mathrm{H}_{2} \mathrm{O}_{2}$, followed by plotting their concentrations on $x$-axis and their respective absorbance on $y$-axis (Fig. 2a). The sTOS in cases and controls are presented using dot plot in Fig. 2b. RVVI $\left(13.74 \pm 7.61 \mu \mathrm{mol} \mathrm{H}_{2} \mathrm{O}_{2}\right.$ Equiv/L) and its subtypes BV (12.72 $\pm 6.84 \mu \mathrm{mol} \mathrm{H}_{2} \mathrm{O}_{2}$ Equiv/L), VVC $(12.85 \pm 7.28$ $\mu$ mol $\mathrm{H}_{2} \mathrm{O}_{2}$ Equiv/L), and $\mathrm{MI}\left(11.08 \pm 4.31 \mu \mathrm{mol} \mathrm{H}_{2} \mathrm{O}_{2}\right.$ Equiv/L) showed significantly low level of sTOS as compared to controls $\left(20.95 \pm 11.71 \mu \mathrm{mol} \mathrm{H}_{2} \mathrm{O}_{2}\right.$ Equiv/L) at $p=0.000$. No other significant difference was found.

\section{Oxidative stress index}

sOSI was assessed in cases and controls by calculating ratio of TOS to TAC of each category. The sOSI of RVVI (0.0200 \pm 0.0027$)$, BV (0.0239 \pm 0.0093$)$, VVC (0.0139 \pm 0.0024$)$, MI $(0.0238 \pm 0.0147)$, and controls $(0.0224 \pm 0.0063)$ are presented using dot plot in Fig. 3 . Significant low sOSI was observed in RVVI $(p=0.001)$ and VVC $(p=0.000)$ as compared to controls. Significant low sOSI were observed in VVC as compared to $\operatorname{RVVI}(p=0.000)$, BV $(p=0.000)$, and MI $(p=0.000)$. However, high sOSI were observed in BV $(p=0.000)$ and MI $(p=0.006)$ as compared to RVVI.

\section{MBL and Dectin-1}

The distribution of sMBL and sDectin-1 levels in RVVI, RVVI types, and healthy controls have been reported previously (Kalia et al., 2017, 2018). RVVI (793.4 \pm 539.3 $\mathrm{ng} / \mathrm{ml})$ and its subtypes BV $(744.1 \pm 481.5 \mathrm{ng} / \mathrm{ml})$, VVC $(595.9 \pm 499.74 \mathrm{ng} / \mathrm{ml})$, and MI $(842.4 \pm 556.14 \mathrm{ng} / \mathrm{ml})$ showed significantly low level of sMBL as compared to controls $(1128.4 \pm 518.00 \mathrm{ng} / \mathrm{ml})$. RVVI $(0.408 \pm 0.185$ $\mathrm{ng} / \mathrm{ml})$ and its subtypes BV $(0.343 \pm 0.151 \mathrm{ng} / \mathrm{ml}), \mathrm{VVC}$ $(0.412 \pm 0.183 \mathrm{ng} / \mathrm{ml})$, and MI $(0.353 \pm 0.144 \mathrm{ng} / \mathrm{ml})$ showed significantly high level of sDectin-1 as compared to controls $(0.170 \pm 0.096 \mathrm{ng} / \mathrm{ml})$.

\section{Correlation}

Pearson's correlation analysis of serum biomarkers was assessed in RVVI, RVVI types, and controls (Table 2). In RVVI, a significant negative correlation was found between pairs including sMBL/sTAC and sOSI/sTAC. In addition, significant positive correlations were found between pairs including sDectin-1/sTAC, sTOS/sTAC, and sOSI/sTOS. In BV, significant positive correlations were found between pairs sDectin-1/sTAC and sTOS/sOSI while, significant negative correlation was found between sTAC and sOSI. In VVC, significant positive correlations were found between pairs sDectin-1/sTAC and sTOS/ 

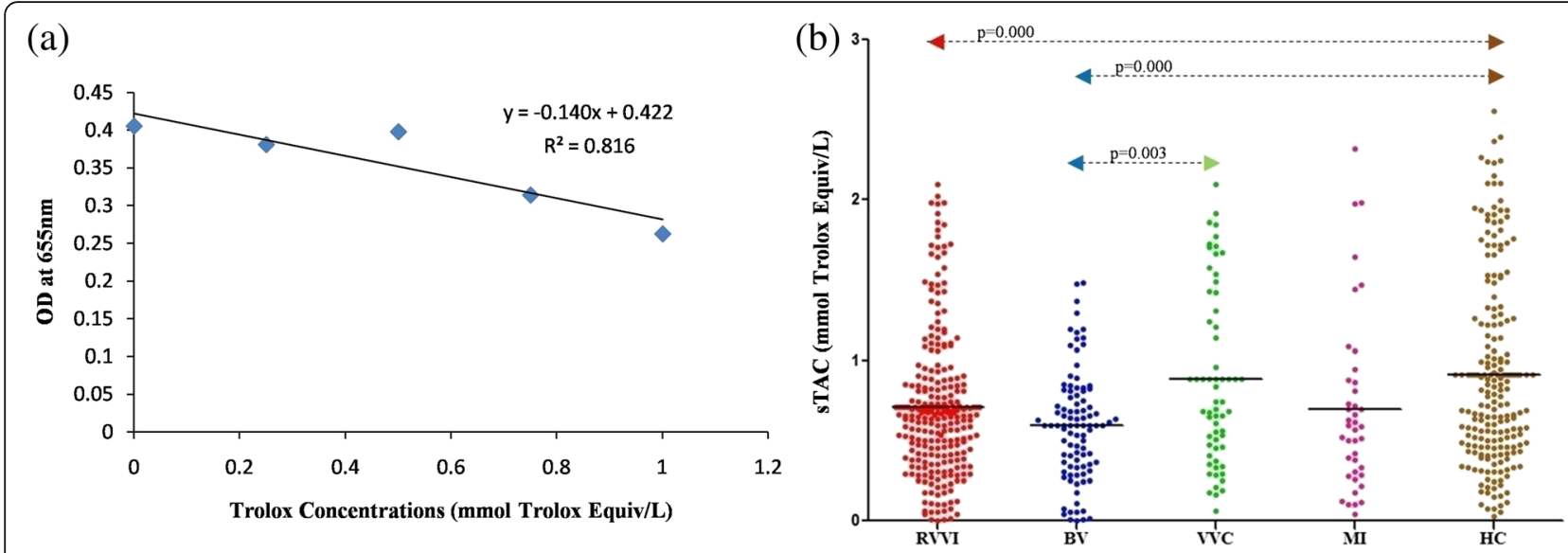

Fig. 1 a Standard curve for quantitative evaluation of STAC. $\mathbf{b}$ STAC in different clinical categories of RWI and healthy controls (HC). Dot plot presenting the distribution of STAC in patients and controls. Horizontal line signifies the mean value

sOSI while, significant negative correlations were found between pairs including sDectin-1/sOSI and sTAC/sOSI. In MI, significant positive correlation was found between sTAC and sTOS while, significant negative correlations were found between pairs including sMBL/sTOS and sTAC/sOSI. In controls, significant positive correlations were found between pairs sMBL/sTOS, sMBL/sOSI, and sTOS/sOSI while, significant negative correlations were found between pairs including sDectin-1/sTAC, sTAC/ sTOS, and sTAC/sOSI.

Pearson's correlation analysis of serum biomarkers with confounding parameters was assessed in RVVI, RVVI types, and controls (Table 3). In RVVI, sMBL exhibited significant positive correlation with age at which sexual activity was initiated. Also, sTAC exhibited significant negative correlation with age, RCBG, and age of initiation of sexual activity. No significant correlations of confounding parameters were found with sDectin-1, sTOS, and sOSI. In BV sMBL, sDectin-1 and sTAC were found to be significantly associated with age at which sexual activity was initiated. Also, significant positive correlation of sDectin-1 and sOSI was found with RCBG and duration of infection respectively. In VVC, sMBL exhibit significant positive correlation with duration of infection. sDectin-1 was found to be significantly negatively correlated with age, RCBG, and age of initiation of sexual activity. sTAC exhibit significant negative correlation with age of initiation of sexual activity. sTOS exhibit significant positive correlation with age and RCBG. In MI, sMBL and sTOS were found to be significantly associated with age of initiation of sexual activity and duration of infection. Also, sOSI was found to be negatively correlated with age of initiation of sexual activity. In controls, only positive correlation was found between
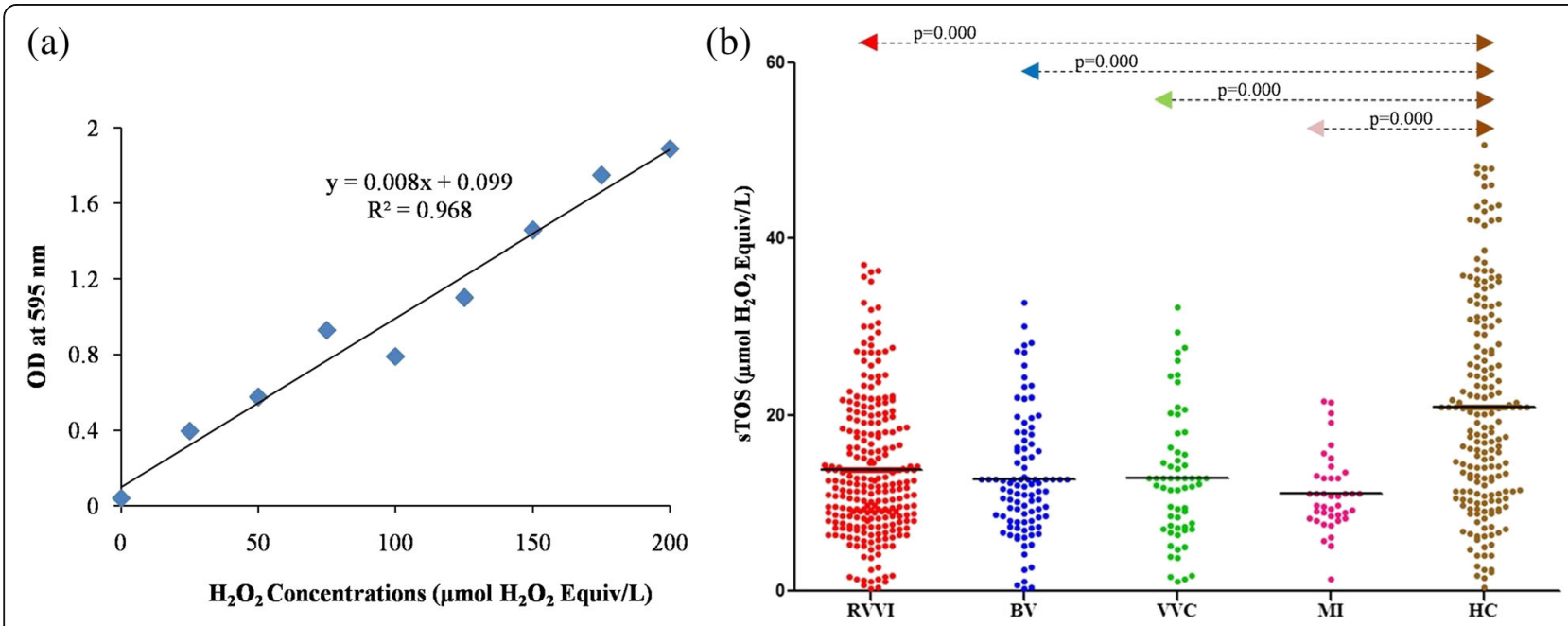

Fig. 2 a Standard curve for quantitative evaluation of sTOS. b sTOS in different clinical categories of RWI and healthy controls (HC). Dot plot presenting the distribution of sTOS in patients and controls. Horizontal line signifies the mean value 


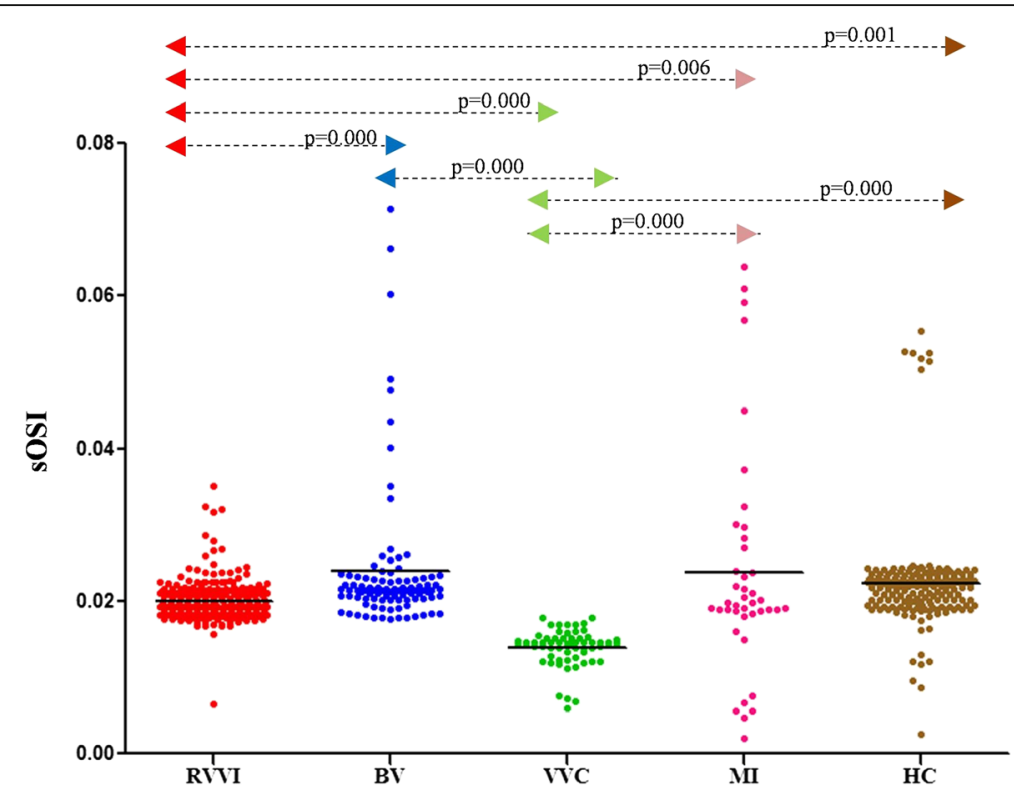

Fig. $3 \mathrm{sOSI}$ in different clinical categories of RWI and healthy controls ( $\mathrm{HC})$. Dot plot presenting the distribution of sOSI levels in patients and controls. Horizontal line signifies the mean value

sTOS and RCBG. No other significant correlations of confounding parameters were found with sMBL, sDectin-1, sTAC, and sOSI.

\section{Regression}

In order to assess the confounding effects of factors, multiple linear regression analysis was performed. First model, where one of the serum biomarkers was taken as dependent variable and the rest other variables were taken as independent variables (Table 4). It was found that all these factors were independent significant predictors of each other in all the categories when serum oxidative stress markers were taken as dependent variables. However, all these factors were independent significant predictors of sMBL only in controls and of sDectin-1 in RVVI, VVC, and controls. In the second model sMBL, sDectin-1, sTAC, sTOS, and sOSI were the dependent variables and parameters including age, RCBG, age of initiation of sexual activity, and duration of infection were taken as independent factors (Table 5). It was found that all these factors were independent significant predictors of sTAC in RVVI, sMBL, and sTAC in BV as well as MI and sMBL and sDectin-1 in VVC. However, these factors do not show significant regression on serum biomarkers in controls.

\section{Discussion}

Reactive oxidants have been suggested to be involved in various defense mechanisms against pathogens, leading to the state of oxidative stress, with significant biological consequences (Lugrin et al., 2014). Different studies have documented high ROS production by neutrophils in response to BV-associated bacteria, C. albicans, and $T$. vaginalis infection and suggested to play an important role in maintaining low burden of infection ( $\mathrm{Li}$ et al., 2012b; de Souza Bonfim-Mendonça P, Ratti BA, Godoy JD, 2014; Frasson et al., 2012; Svobodová et al., 2012; Johnson et al., 2017). To assess the status of oxidative stress by studying all oxidants/anti-oxidants parameters is tedious, time-consuming, and uneconomical. In addition, it is not relevant to investigate various antioxidants, looking one in isolation from the rest, because they can have synergistic or antagonistic effects and may not be the most effective strategy when trying to predict an individual's risk of developing disease. For these reasons, recent studies have used measures of TAC, TOS, and OSI (Erel, 2004; Erel, 2005). These methods can provide information on an individual's overall oxidant and anti-oxidants status and thus investigated in the present study in relation to risk of RVVI and its types.

Both TAC and TOS were found to be significantly low in RVVI cases and its types comparative to controls. An assumption that an increased TOS reflects increased production of ROS is rather questionable. Most ROS produced by neutrophils and macrophages either react with target proteins or are neutralized by anti-oxidants. A separate evaluation of our results for TOS and TAC, showed that apparently these cases did not experience oxidative stress (OS), as the level of both TAC and TOS was low in cases than controls. Therefore, it is important to evaluate not only the concentrations of oxidants and anti-oxidants separately, but also their relationship 
Table 2 Correlation analysis of serum biomarkers in RWI, RWI types, and controls

\begin{tabular}{|c|c|c|c|c|c|c|c|c|c|c|}
\hline & \multicolumn{2}{|l|}{ sMBL } & \multicolumn{2}{|c|}{ sDectin-1 } & \multicolumn{2}{|l|}{ sTAC } & \multicolumn{2}{|l|}{ sTOS } & \multicolumn{2}{|l|}{ sOSI } \\
\hline & $r$ & $p$ & $r$ & $p$ & $r$ & $p$ & $r$ & $p$ & $r$ & $p$ \\
\hline \multicolumn{11}{|l|}{ RWI } \\
\hline$s M B L$ & - & - & -0.012 & 0.423 & -0.136 & $0.015^{*}$ & 0.015 & 0.408 & 0.005 & 0.467 \\
\hline sDectin-1 & -0.012 & 0.423 & - & - & 0.216 & $0.000 * * *$ & 0.077 & 0.109 & -0.070 & 0.132 \\
\hline sTAC & -0.136 & $0.015^{*}$ & 0.216 & $0.000 * * *$ & - & - & 0.109 & $0.040^{*}$ & -0.498 & $0.000 * * *$ \\
\hline sTOS & 0.015 & 0.408 & 0.077 & 0.109 & 0.109 & $0.04^{*}$ & - & - & 0.387 & $0.000 * * *$ \\
\hline sOSI & 0.005 & 0.467 & -0.070 & 0.132 & -0.498 & $0.000^{* * *}$ & 0.387 & $0.000 * * *$ & - & - \\
\hline \multicolumn{11}{|c|}{ BV } \\
\hline sMBL & - & - & 0.045 & 0.330 & -0.077 & 0.227 & -0.009 & 0.467 & -0.016 & 0.439 \\
\hline sDectin-1 & 0.045 & 0.330 & - & - & 0.218 & $0.016^{*}$ & -0.004 & 0.485 & -0.050 & 0.312 \\
\hline STAC & -0.077 & 0.227 & 0.218 & $0.016^{*}$ & - & - & 0.145 & 0.079 & -0.468 & $0.000 * * *$ \\
\hline sTOS & -0.009 & 0.467 & -0.004 & 0.485 & 0.145 & 0.079 & - & - & 0.266 & $0.004 * *$ \\
\hline sOSI & -0.016 & 0.439 & -0.050 & 0.312 & -0.468 & $0.000 * * *$ & 0.266 & $0.004^{* *}$ & - & - \\
\hline \multicolumn{11}{|l|}{ WC } \\
\hline sMBL & - & - & -0.198 & 0.062 & -0.146 & 0.129 & 0.097 & 0.226 & 0.103 & 0.212 \\
\hline sDectin-1 & -0.198 & 0.062 & - & - & 0.377 & $0.001 * * *$ & 0.060 & 0.322 & -0.243 & $0.029 *$ \\
\hline STAC & -0.146 & 0.129 & 0.377 & $0.001 * * *$ & - & - & 0.142 & 0.136 & -0.488 & $0.000 * * *$ \\
\hline sTOS & 0.097 & 0.226 & 0.060 & 0.322 & 0.142 & 0.136 & - & - & 0.458 & $0.000 * * *$ \\
\hline sOSI & 0.103 & 0.212 & -0.243 & $0.029^{*}$ & -0.488 & $0.000 * * *$ & 0.458 & $0.000 * * *$ & - & - \\
\hline \multicolumn{11}{|l|}{ Ml } \\
\hline sMBL & - & - & 0.031 & 0.425 & -0.156 & 0.166 & -0.320 & $0.021 *$ & -0.074 & 0.324 \\
\hline sDectin-1 & 0.031 & 0.425 & - & - & 0.242 & 0.064 & 0.074 & 0.323 & -0.023 & 0.443 \\
\hline sTAC & -0.156 & 0.166 & 0.242 & 0.064 & - & - & 0.327 & $0.018^{*}$ & -0.564 & $0.000^{* * *}$ \\
\hline sTOS & -0.320 & $0.021 *$ & 0.074 & 0.323 & 0.327 & $0.018^{*}$ & - & - & 0.175 & 0.136 \\
\hline sOSI & -0.074 & 0.324 & -0.023 & 0.443 & -0.564 & $0.000^{* * *}$ & 0.175 & 0.136 & - & - \\
\hline \multicolumn{11}{|l|}{$\mathrm{HC}$} \\
\hline sMBL & - & - & -0.060 & 0.199 & -0.004 & 0.477 & 0.256 & $0.000 * * *$ & 0.194 & $0.003 * *$ \\
\hline sDectin-1 & -0.060 & 0.199 & - & - & -0.247 & $0.000^{* * *}$ & -0.050 & 0.241 & 0.069 & 0.165 \\
\hline STAC & -0.004 & 0.477 & -0.247 & $0.000^{* * *}$ & - & - & -0.124 & $0.039 *$ & -0.550 & $0.000 * * *$ \\
\hline sTOS & 0.256 & $0.000 * * *$ & -0.050 & 0.241 & -0.124 & $0.039 *$ & - & - & 0.586 & $0.000 * * *$ \\
\hline sOSI & 0.194 & $0.003^{* *}$ & 0.069 & 0.165 & -0.550 & $0.000^{* * *}$ & 0.586 & $0.000 * * *$ & - & - \\
\hline
\end{tabular}

${ }^{*} p \leq 0.05,{ }^{* *} p \leq 0.01, * * * p \leq 0.001$

through a proportion or ratio, because it is the imbalance between oxidants and anti-oxidants that defines the concept of OS (Gupta et al., 2016). The first approach using this ratio was made in human medicine by Sharma et al. (Sharma et al., 1999). The study proposed the use of the ratio oxidants/anti-oxidants as an index indicative of an individual's risk of developing disease. Thus, an increase in the ratio indicates risk of OS because of the increase in ROS production, while decrease in ratio represents the increased antioxidant potential, the socalled anti-oxidative stress (AOS) (Birben et al., 2012; Poljsak \& Milisav, 2012). The term "AOS" was used for the first time by Dundar and Aslan for the negative effects of anti-oxidants (Dundar \& Aslan, 2000). Thus, in the present study, oxidative status was studied by a combined evaluation of oxidants and anti-oxidants.

OSI, that reflects total oxidant/antioxidant balance, was found to be significantly low in RVVI and VVC as compared to controls, indicating reduced ROS production as a possible risk factor for the rapid progression of RVVI. In consonance to these findings, studies have reported reduced concentrations of NO metabolites and iNOS expression in vaginal fluids of RVVC and TV cases relative to controls and $T$. vaginalis infected asymptomatic women respectively (Babula et al., 2005; Malla et al., 2004; Yadav et al., 2006). However, the findings of the present study are contradictory to a study that found no significant difference in ROS concentration in the amniotic fluid 
Table 3 Correlation analysis of serum biomarkers with confounding parameters in RWI, RWI types, and controls

\begin{tabular}{|c|c|c|c|c|c|c|c|c|c|c|}
\hline & \multicolumn{2}{|l|}{ SMBL } & \multicolumn{2}{|c|}{ sDectin-1 } & \multicolumn{2}{|l|}{ STAC } & \multicolumn{2}{|l|}{ sTOS } & \multicolumn{2}{|l|}{ sOSI } \\
\hline & $r$ & p & $r$ & p & r & p & $r$ & $p$ & $r$ & p \\
\hline \multicolumn{11}{|l|}{ RWI } \\
\hline Age & -0.006 & 0.460 & -0.076 & 0.112 & -0.104 & $0.048^{*}$ & -0.073 & 0.122 & 0.052 & 0.204 \\
\hline RCBG & 0.016 & 0.401 & -0.062 & 0.169 & -0.125 & $0.023^{*}$ & -0.021 & 0.368 & 0.006 & 0.465 \\
\hline Age of initiation of sexual activity & 0.129 & $0.019 *$ & -0.153 & 0.163 & -0.233 & $0.000^{* * *}$ & -0.097 & 0.060 & 0.023 & 0.354 \\
\hline Duration of infection & 0.073 & 0.121 & -0.064 & 0.139 & -0.019 & 0.379 & -0.016 & 0.399 & 0.016 & 0.401 \\
\hline \multicolumn{11}{|l|}{ BV } \\
\hline Age & -0.002 & 0.491 & -0.095 & 0.178 & -0.153 & 0.067 & -0.164 & 0.054 & 0.058 & 0.286 \\
\hline RCBG & 0.050 & 0.314 & 0.196 & $0.027^{*}$ & -0.124 & 0.113 & -0.108 & 0.146 & -0.079 & 0.222 \\
\hline Age of initiation of sexual activity & 0.280 & $0.003^{* *}$ & -0.187 & $0.034^{*}$ & -0.321 & $0.001^{* * *}$ & -0.097 & 0.173 & 0.129 & 0.104 \\
\hline Duration of infection & -0.047 & 0.323 & -0.095 & 0.178 & -0.107 & 0.149 & -0.074 & 0.237 & 0.169 & $0.049 *$ \\
\hline \multicolumn{11}{|l|}{ WC } \\
\hline Age & 0.043 & 0.369 & -0.348 & $0.003^{* *}$ & -0.083 & 0.261 & 0.217 & $0.045^{*}$ & 0.205 & 0.055 \\
\hline RCBG & -0.005 & 0.486 & -0.227 & $0.038^{*}$ & -0.146 & 0.128 & 0.212 & $0.049 *$ & 0.123 & 0.170 \\
\hline Age of initiation of sexual activity & 0.132 & 0.154 & -0.285 & $0.012^{*}$ & -0.303 & $0.008^{* *}$ & 0.151 & 0.121 & 0.183 & 0.077 \\
\hline Duration of infection & 0.357 & $0.002^{* *}$ & -0.105 & 0.208 & 0.157 & 0.112 & -0.010 & 0.471 & -0.171 & 0.092 \\
\hline \multicolumn{11}{|l|}{ Ml } \\
\hline Age & 0.005 & 0.459 & 0.026 & 0.436 & -0.132 & 0.206 & -0.247 & 0.060 & 0.040 & 0.401 \\
\hline RCBG & -0.022 & 0.445 & -0.051 & 0.375 & -0.208 & 0.096 & -0.159 & 0.160 & 0.008 & 0.480 \\
\hline Age of initiation of sexual activity & 0.459 & $0.001^{* * *}$ & 0.103 & 0.261 & -0.034 & 0.417 & -0.354 & $0.012^{*}$ & -0.318 & $0.021^{*}$ \\
\hline Duration of infection & -0.267 & $0.046^{*}$ & -0.207 & 0.097 & -0.046 & 0.388 & -0.335 & $0.016^{*}$ & 0.024 & 0.441 \\
\hline \multicolumn{11}{|l|}{$\mathrm{HC}$} \\
\hline Age & -0.090 & 0.101 & 0.045 & 0.263 & 0.044 & 0.265 & -0.032 & 0.323 & -0.093 & 0.094 \\
\hline RCBG & -0.054 & 0.221 & -0.071 & 0.157 & -0.022 & 0.378 & 0.158 & $0.012^{*}$ & 0.051 & 0.236 \\
\hline Age of initiation of sexual activity & 0.014 & 0.421 & 0.026 & 0.354 & 0.036 & 0.307 & 0.027 & 0.353 & -0.005 & 0.473 \\
\hline
\end{tabular}

of women with and without BV (Bogavac et al., 2012) and to the study where significantly high concentration of ROS was found in the vaginal discharge of BV patients, relative to healthy women depicting their active role in defense mechanism (Chen et al., 2015). However, all these studies do not represent the total status of oxidants or anti-oxidants in serum of patients, since these studies were focused on one or two oxidants or anti-oxidants and thus, showed changes only in few oxidative markers, that too in different biological fluids, i.e., vaginal discharge and amniotic fluid. To date, there are no studies that showed an association of TAC, TOS, and OSI in RVVI and its types in serum or in any other biological fluids. Also, correlation and regression analysis showed an obvious and expected relationship between different parameters of oxidative stress in the present study, i.e., positive association between pairs including TAC/TOS and TOS/OSI while negative association between TAC/OSI (Birben et al., 2012; Reiter, 1995; Halliwell, 1996).

The reduced ROS production observed in cases of the present study is may be due to defective inflammatory response. This is because both OS and different inflammatory stages stimulate each other as a part of defense mechanism for the ultimate killing of pathogens by effectors cells (Lugrin et al., 2014; Pacher et al., 2007). In fact, both MBL and Dectin-1, the two important PRRs, have been shown to mediate the release of ROS as a part of immune responses generated against pathogens (Underhill et al., 2005; Lima-Junior et al., 2017; Hartshorn et al., 1993; Kawasaki et al., 2000; Gantner et al., 2003; Gadjeva et al., 2004). Additionally, a study has shown, increased intracellular expression of Dectin-1 and consequent ROS production as a result of MBLarbitrated opsonophagocytosis of pathogens, showing the coupling between two CLRs for optimal ROS generation in response to pathogens ( $\mathrm{Li}$ et al., 2012b). However, in the present study, low levels of both SMBL and oxidative stress biomarkers, while high levels of sDectin1 were observed in RVVI and its types relative to controls, suggesting the defective collaboration between these PRRs for optimal ROS production, perhaps due to low sMBL levels. Also, significant but unexpected weak 
Table 4 Multiple linear regression analysis of serum biomarkers in RWI, RWI types and controls

\begin{tabular}{|c|c|c|c|c|c|c|c|c|c|c|c|}
\hline \multirow[t]{2}{*}{ MLR equations } & \multicolumn{8}{|c|}{$\beta$-regression coefficients } & \multirow[t]{2}{*}{$r$} & \multirow[t]{2}{*}{$F$} & \multirow[t]{2}{*}{$p$} \\
\hline & $\beta_{1}$ & $p$ & $\beta_{2}$ & $p$ & $\beta_{3}$ & $p$ & $\beta_{4}$ & $p$ & & & \\
\hline \multicolumn{12}{|l|}{ RWI } \\
\hline $\begin{array}{l}\mathrm{sMBL}=953.8+52.39 X_{\mathrm{Dec}}-290.95 X_{\mathrm{TAC}} \\
+6.24 X_{\mathrm{TOS}}-314.89 X_{\mathrm{OSI}}\end{array}$ & 0.018 & 0.772 & -0.218 & $0.006 * *$ & 0.090 & 0.217 & -0.137 & 0.101 & 0.173 & 1.954 & 0.102 \\
\hline $\begin{array}{l}\text { sDectin-1 }=0.315+0.0063 X_{\mathrm{MBL}} \\
+0.095 X_{\mathrm{TAC}}+0.001 X_{\mathrm{TOS}}+0.219 X_{\mathrm{OSI}}\end{array}$ & 0.018 & 0.772 & 0.227 & $0.004^{* *}$ & 0.041 & 0.566 & 0.027 & 0.744 & 0.224 & 3.32 & $0.010^{* *}$ \\
\hline $\begin{array}{l}\text { sTAC }=0.725+0.000 X_{\text {MBL }}+0.343 X_{\text {Dec }} \\
+0.020 X_{\text {TOS }}-11.89 X_{\text {OSI }}\end{array}$ & -0.136 & $0.006^{* *}$ & 0.145 & $0.004^{* *}$ & 0.340 & $0.000^{* * * *}$ & -0.619 & $0.000^{* * *}$ & 0.629 & 41.32 & $0.000 * * *$ \\
\hline $\begin{array}{l}\mathrm{sTOS}=1.940+0.001 X_{\mathrm{MBL}}+1.293 X_{\mathrm{Dec}} \\
+7.012 X_{\mathrm{TAC}}+196.09 X_{\mathrm{OSI}}\end{array}$ & 0.067 & 0.217 & 0.032 & 0.566 & 0.406 & $0.000^{* * * *}$ & 0.592 & $0.000 * * *$ & 0.526 & 24.23 & $0.000 * * *$ \\
\hline $\begin{array}{l}\text { sOSI }=0.032-0.003 X_{\mathrm{MBL}}+0.002 X_{\mathrm{Dec}} \\
-0.029 X_{\mathrm{TAC}}+0.001 X_{\mathrm{TOS}}\end{array}$ & -0.077 & 0.101 & 0.016 & 0.144 & -0.561 & $0.000^{* * * *}$ & 0.449 & $0.000^{* * * *}$ & 0.672 & 52.12 & $0.000 * * *$ \\
\hline \multicolumn{12}{|l|}{ BV } \\
\hline $\begin{array}{l}\mathrm{SMBL}=808.15+180.75 X_{\text {Dec }}-153.73 X_{\text {TAC }} \\
+2.141 X_{\text {TOS }}-1854.2 X_{\text {OSI }}\end{array}$ & 0.071 & 0.506 & -0.137 & 0.282 & 0.034 & 0.763 & -0.086 & 0.502 & 0.122 & 0.346 & 0.846 \\
\hline $\begin{array}{l}\text { sDectin-1 }=0.263+0.026 X_{\mathrm{MBL}}+0.123 X_{\mathrm{TAC}} \\
-0.002 X_{\mathrm{TOS}}+0.851 X_{\mathrm{OSI}}\end{array}$ & 0.068 & 0.506 & 0.280 & $0.023^{*}$ & -0.070 & 0.527 & 0.100 & 0.422 & 0.243 & 1.445 & 0.225 \\
\hline $\begin{array}{l}\text { STAC }=0.639-0.081 X_{\mathrm{MBL}}+0.445 X_{\mathrm{Dec}} \\
+0.016 X_{\mathrm{TOS}}-10.351 X_{\mathrm{OSI}}\end{array}$ & -0.092 & 0.282 & 0.196 & $0.023^{*}$ & 0.287 & $0.002^{* *}$ & -0.535 & $0.000^{* * * *}$ & 0.584 & 11.924 & $0.000 * * *$ \\
\hline $\begin{array}{l}\text { STOS }=5.283+0.000 X_{\text {MBL }}-2.537 X_{\text {Dec }} \\
+6.512 X_{\text {TAC }}+150.14 X_{\text {OSI }}\end{array}$ & 0.029 & 0.763 & -0.062 & 0.527 & 0.363 & $0.002^{* *}$ & 0.433 & $0.000^{* * *}$ & 0.409 & 4.625 & $0.002^{* * *}$ \\
\hline $\begin{array}{l}\text { SOSI }=0.033-0.0026 X_{\mathrm{MBL}}+0.008 X_{\mathrm{Dec}} \\
-0.028 X_{\mathrm{TAC}}+0.001 X_{\mathrm{TOS}}\end{array}$ & -0.057 & 0.502 & 0.070 & 0.422 & -0.537 & $0.000^{* * * *}$ & 0.343 & $0.000^{* * *}$ & 0.583 & 11.82 & $0.000 * * *$ \\
\hline \multicolumn{12}{|l|}{ WC } \\
\hline $\begin{array}{l}\mathrm{SMBL}=786.07-425.19 X_{\mathrm{Dec}}-121.667 X_{\mathrm{TAC}} \\
+10.41 X_{\mathrm{TOS}}-1782.2 X_{\mathrm{OSI}}\end{array}$ & -0.173 & 0.218 & -0.147 & 0.394 & 0.169 & 0.307 & -0.088 & 0.638 & 0.251 & 0.960 & 0.437 \\
\hline $\begin{array}{l}\text { sDectin-1 }=0.368-0.062 X_{\mathrm{MBL}}+0.092 X_{\mathrm{TAC}} \\
+0.003 X_{\mathrm{TOS}}-1.151 X_{\mathrm{OSI}}\end{array}$ & -0.153 & 0.218 & 0.273 & 0.090 & 0.100 & 0.520 & -0.140 & 0.426 & 0.416 & 2.983 & $0.026^{*}$ \\
\hline $\begin{array}{l}\text { STAC }=0.676+0.000 X_{\mathrm{MBL}}+0.539 X_{\mathrm{Dec}} \\
+0.032 X_{\mathrm{TOS}^{-1}}-15.46 X_{\mathrm{OSI}}\end{array}$ & -0.087 & 0.394 & -0.181 & 0.090 & 0.428 & $0.000^{* * * *}$ & -0.631 & $0.000^{* * *}$ & 0.671 & 11.66 & $0.000 * * *$ \\
\hline $\begin{array}{l}\text { STOS }=-0.416+0.002 X_{\mathrm{MBL}}+2.898 X_{\mathrm{Dec}} \\
+6.268 X_{\mathrm{TAC}}+227.099 X_{\mathrm{OSI}}\end{array}$ & 0.108 & 0.307 & 0.073 & 0.520 & 0.469 & $0.000^{* * * *}$ & 0.693 & $0.000^{* * * *}$ & 0.631 & 9.447 & $0.000 * * *$ \\
\hline $\begin{array}{l}\text { sOSI }=0.028-0.0021 X_{\text {MBL }}-0.010 X_{\text {Dec }} \\
-0.022 X_{\text {TAC }}+0.002 X_{\text {TOS }}\end{array}$ & -0.044 & 0.638 & -0.080 & 0.426 & -0.542 & $0.000^{* * * *}$ & 0.544 & $0.000^{* * * *}$ & 0.727 & 15.95 & $0.000 * * *$ \\
\hline \multicolumn{12}{|l|}{ MI } \\
\hline $\begin{array}{l}\text { sMBL }=1101.84+294.18 X_{\text {Dec }}- \\
164.99 X_{\text {TAC }}-18.93 X_{\text {TOS }}-1980.7 X_{\text {OSI }}\end{array}$ & 0.085 & 0.606 & -0.159 & 0.497 & -0.254 & 0.184 & -0.117 & 0.593 & 0.342 & 1.195 & 0.330 \\
\hline $\begin{array}{l}\text { sDectin- } 1=0.239+0.0254 X_{\text {MBL }} \\
+0.122 X_{\text {TAC }}-0.002 X_{\text {TOS }}+1.105 X_{\text {OSI }}\end{array}$ & 0.088 & 0.606 & 0.406 & 0.082 & -0.071 & 0.719 & 0.225 & 0.308 & 0.301 & 0.898 & 0.476 \\
\hline $\begin{array}{l}\text { STAC }=0.449-0.078 X_{\mathrm{MBL}}+0.668 X_{\mathrm{Dec}} \\
+0.029 X_{\mathrm{TOS}}-10.389 X_{\mathrm{OSI}}\end{array}$ & -0.081 & 0.497 & 0.201 & 0.082 & 0.398 & $0.002^{* *}$ & -0.636 & $0.000^{* * * *}$ & 0.742 & 11.01 & $0.000 * * *$ \\
\hline $\begin{array}{l}\text { sTOS }=6.754-0.003 X_{\mathrm{MBL}}-2.384 X_{\mathrm{Dec}} \\
+8.172 X_{\mathrm{TAC}}+111.79 X_{\mathrm{OSI}}\end{array}$ & -0.191 & 0.184 & -0.052 & 0.719 & 0.588 & $0.002^{* *}$ & 0.492 & $0.006^{* * *}$ & 0.580 & 4.55 & $0.004^{* *}$ \\
\hline $\mathrm{sOSI}=0.034-0.004 X_{\mathrm{MBL}}+0.026 X_{\mathrm{Dec}}-0.045 X_{\mathrm{TAC}}+0.002 X_{\mathrm{TOS}}$ & -0.539 & 0.593 & 1.034 & 0.308 & -5.595 & $0.000^{* * *}$ & 2.893 & $0.006^{* *}$ & 0.695 & 8.387 & $0.000 * * *$ \\
\hline \multicolumn{12}{|l|}{$\mathrm{HC}$} \\
\hline $\begin{array}{l}\text { sMBL }=847.39-326.7 X_{\text {Dec }}+112.62 X_{\text {TAC }} \\
+12.81 X_{\text {TOS }}+4266.3 X_{\text {OSI }}\end{array}$ & -0.039 & 0.582 & 0.082 & 0.351 & 0.181 & $0.035^{*}$ & 0.132 & 0.209 & 0.275 & 4.05 & $0.004 * *$ \\
\hline $\begin{array}{l}\text { sDectin-1 }=0.233-0.0046 \mathrm{X}_{\text {MBL }}-0.046 \mathrm{X}_{\text {TAC }} \\
+0.000 \mathrm{X}_{\text {TOS }}-0.208 \mathrm{X}_{\text {OSI }}\end{array}$ & -0.039 & 0.582 & -0.282 & $0.001 * * *$ & -0.043 & 0.631 & -0.054 & 0.610 & 0.266 & 3.750 & $0.006^{* *}$ \\
\hline $\begin{array}{l}\text { STAC }=1.284+0.039 X_{\mathrm{MBL}}-1.116 X_{\mathrm{Dec}} \\
+0.013 X_{\mathrm{TOS}}-16.59 X_{\mathrm{OSI}}\end{array}$ & 0.053 & 0.351 & -0.182 & $0.001 * * *$ & 0.266 & $0.000^{* * *}$ & -0.704 & $0.000^{* * *}$ & 0.632 & 32.88 & $0.000 * * *$ \\
\hline $\begin{array}{l}\text { sTOS }=4.316+0.002 X_{\text {MBL }}-3.321 X_{\text {Dec }} \\
+5.183 X_{\text {TAC }}+333.820 X_{\text {OSI }}\end{array}$ & 0.119 & $0.035^{*}$ & -0.027 & 0.631 & 0.259 & $0.000^{* * * *}$ & 0.707 & $0.000^{* * *}$ & 0.644 & 34.99 & $0.000 * * *$ \\
\hline $\begin{array}{l}\mathrm{sOSI}=0.026+0.018 X_{\mathrm{MBL}}-0.006 X_{\mathrm{Dec}} \\
-0.021 X_{\text {TAC }}+0.001 X_{\text {TOS }}\end{array}$ & 0.060 & 0.209 & -0.024 & 0.610 & -0.493 & 0.000 & 0.508 & $0.000^{* * * *}$ & 0.761 & 68.09 & $0.000 * * *$ \\
\hline
\end{tabular}

$X_{M B L}=s M B L(n g / m l), X_{D e C}=s$ Dectin-1 $(\mathrm{ng} / \mathrm{ml}), X_{T A C}=\mathrm{TAC}\left(\mathrm{mmol}\right.$ Trolox Equiv/L), $X_{T O S}=\mathrm{TOS}\left(\mu \mathrm{mol} \mathrm{H}_{2} \mathrm{O}_{2}\right.$ Equiv/L), $X_{O S I}=$ OSI (arbitrary unit); beta regression coefficients: $\beta_{1}, \beta_{2}, \beta_{3}, \beta_{4}$ respectively based on $X$ variables given in MLR equations; $r=$ multiple correlation coefficient; ${ }^{*}, *$, and ${ }^{* * *}$ indicate significant at $p \leq$ $0.05, p \leq 0.01$, and $p \leq 0.001$ respectively 
Table 5 Multiple linear regression analysis showing the effect of confounding parameters on serum biomarkers in RWl, RWI types, and controls

\begin{tabular}{|c|c|c|c|c|c|c|c|c|c|c|c|}
\hline \multirow[t]{2}{*}{ MLR equations } & \multicolumn{8}{|c|}{$\beta$-regression coefficients } & \multirow[t]{2}{*}{$r$} & \multirow[t]{2}{*}{$F$} & \multirow[t]{2}{*}{$p$} \\
\hline & $\overline{\beta_{1}}$ & $p$ & $\beta_{2}$ & $p$ & $\beta_{3}$ & $p$ & $\beta_{4}$ & $p$ & & & \\
\hline \multicolumn{12}{|l|}{ RWI } \\
\hline $\begin{array}{l}\mathrm{sMBL}=421.126-2.500 X_{1}+0.014 X_{2}+ \\
19.33 X_{3}+9.688 X_{4}\end{array}$ & -0.039 & 0.541 & 0.001 & 0.981 & 0.135 & $0.034^{*}$ & 0.018 & 0.217 & 0.153 & 1.515 & 0.198 \\
\hline $\begin{array}{l}\text { sDectin- } 1=0.610+0.000 X_{1}+0.000 X_{2} \\
-0.007 X_{3}-0.002 X_{4}\end{array}$ & -0.039 & 0.540 & -0.035 & 0.585 & -0.142 & $0.025 *$ & -0.055 & 0.380 & 0.174 & 1.981 & 0.098 \\
\hline $\begin{array}{l}\text { sTAC }=1.445-0.003 X_{1}+0.000 X_{2} \\
-0.026 X_{3}+0.00 X_{4}\end{array}$ & -0.053 & 0.400 & -0.090 & 0.148 & -0.214 & $0.001^{* * *}$ & -0.005 & 0.940 & 0.258 & 4.526 & $0.002^{* *}$ \\
\hline $\begin{array}{l}\text { sTOS }=19.13-0.053 X_{1}-0.084 X_{2} \\
-0.181 X_{3}-0.013 X_{4}\end{array}$ & -0.057 & 0.375 & 0.000 & 0.994 & -0.088 & 0.169 & -0.008 & 0.906 & 0.113 & 0.824 & 0.511 \\
\hline $\begin{array}{l}\text { sOSI }=0.022+0.000 X_{1}-0.0029 X_{2} \\
+0.096 X_{3}+0.0495 X_{4}\end{array}$ & 0.049 & 0.454 & -0.005 & 0.935 & 0.016 & 0.802 & 0.009 & 0.885 & 0.005 & 0.191 & 0.943 \\
\hline \multicolumn{12}{|l|}{ BV } \\
\hline $\begin{array}{l}\text { sMBL }=-141.73-2.692 X_{1}+1.715 X_{2} \\
+38.78 X_{3}-15.87 X_{4}\end{array}$ & -0.051 & 0.622 & 0.076 & 0.452 & 0.323 & $0.003^{* *}$ & -0.128 & 0.229 & 0.317 & 2.562 & $0.044^{*}$ \\
\hline $\begin{array}{l}\text { sDectin- } 1=0.357-0.001 X_{1}+0.002 \\
X_{2}-0.007 X_{3}-0.004 X_{4}\end{array}$ & -0.062 & 0.552 & 0.215 & $0.037^{*}$ & -0.153 & 0.147 & -0.731 & 0.467 & 0.290 & 2.112 & 0.086 \\
\hline $\begin{array}{l}\text { sTAC }=1.727-0.004 X_{1}-0.002 X_{2}-0.033 X_{3} \\
+0.001 X_{4}\end{array}$ & -0.075 & 0.465 & -0.118 & 0.238 & -0.306 & $0.004^{* *}$ & 0.007 & 0.950 & 0.352 & 3.247 & $0.015^{*}$ \\
\hline $\begin{array}{l}\text { sTOS }=23.349-0.117 X_{1}-0.034 X_{2}-0.122 \\
X_{3}-0.018 X_{4}\end{array}$ & -0.139 & 0.198 & -0.093 & 0.371 & -0.063 & 0.556 & -0.009 & 0.935 & 0.199 & 0.952 & 0.438 \\
\hline $\begin{array}{l}\text { sOSI }=0.028+0.0241 X_{1}+0.000 X_{2}+ \\
0.000 X_{3}+0.000 X_{4}\end{array}$ & 0.010 & 0.926 & -0.107 & 0.305 & 0.086 & 0.423 & 0.163 & 0.135 & 0.218 & 1.152 & 0.337 \\
\hline \multicolumn{12}{|l|}{ WC } \\
\hline$s M B L=-14.863+2.938 X_{1}-0.881 X_{2}+23.468 X_{3}+39.35 X_{4}$ & 0.053 & 0.676 & -0.091 & 0.484 & 0.204 & 0.109 & 0.393 & $0.002 * *$ & 0.412 & 0.291 & $0.029^{*}$ \\
\hline $\begin{array}{l}\text { sDectin- } 1=0.944-0.007 X_{1}+0.000 \\
X_{2}-0.013 X_{3}-0.005 X_{4}\end{array}$ & -0.311 & $0.013^{*}$ & -0.077 & 0.541 & -0.272 & $0.029 *$ & -0.134 & 0.264 & 0.466 & 3.950 & $0.007^{*}$ \\
\hline $\begin{array}{l}\text { sTAC }=1.797-0.003 X_{1}-0.001 \\
X_{2}-0.037 X_{3}+0.015 X_{4}\end{array}$ & -0.046 & 0.721 & -0.089 & 0.504 & -0.264 & $0.045^{*}$ & 0.126 & 0.322 & 0.342 & 1.885 & 0.126 \\
\hline $\begin{array}{l}\text { sTOS }=1.410+0.156 X_{1}+0.023 X_{2} \\
+0.209 X_{3}-0.011 X_{4}\end{array}$ & 0.172 & 0.196 & 0.143 & 0.293 & 0.112 & 0.399 & -0.007 & 0.960 & 0.291 & 1.320 & 0.274 \\
\hline $\begin{array}{l}\text { sOSI }=-0.007+0.001 X_{1}+0.027 X_{2} \\
+0.001 X_{3}+0.000 X_{4}\end{array}$ & 0.184 & 0.166 & 0.057 & 0.671 & 0.139 & 0.291 & -0.158 & 0.222 & 0.312 & 1.533 & 0.205 \\
\hline \multicolumn{12}{|l|}{ MI } \\
\hline $\begin{array}{l}\mathrm{sMBL}=-894.80+0.254 X_{1}-0.013 X_{2} \\
+85.56 X_{3}-21.53 X_{4}\end{array}$ & 0.003 & 0.987 & -0.002 & 0.992 & 0.422 & $0.007^{* *}$ & -0.181 & 0.233 & 0.492 & 2.880 & $0.036^{*}$ \\
\hline $\begin{array}{l}\text { sDectin- } 1=0.274+0.002 X_{1}+0.000 X_{2} \\
+0.003 X_{3}-0.007 X_{4}\end{array}$ & 0.070 & 0.699 & -0.062 & 0.733 & 0.059 & 0.726 & -0.197 & 0.247 & 0.228 & 0.493 & 0.741 \\
\hline $\begin{array}{l}\text { sTAC }=1.117-0.004 X_{1}-0.001 X_{2}-0.008 X_{3} \\
+0.004 X_{4}\end{array}$ & -0.047 & 0.796 & -0.185 & 0.313 & -0.039 & 0.814 & -0.031 & 0.856 & 0.218 & 0.047 & 0.774 \\
\hline $\begin{array}{l}\text { sTOS }=35.73-0.296 X_{1}-0.010 X_{2}-0.760 X_{3} \\
+0.496 X_{4}\end{array}$ & -0.224 & 0.166 & -0.096 & 0.548 & -0.280 & 0.062 & 0.311 & $0.040 *$ & 0.523 & 3.391 & $0.019^{*}$ \\
\hline $\begin{array}{l}\text { sOSI }=0.105+0.000 X_{1}-0.098 X_{2}-0.004 X_{3} \\
+0.000 X_{4}\end{array}$ & 0.071 & 0.686 & -0.021 & 0.904 & -0.332 & $0.047^{*}$ & -0.049 & 0.765 & 0.327 & 1.078 & 0.382 \\
\hline \multicolumn{12}{|l|}{$\mathrm{HC}$} \\
\hline $\mathrm{sMBL}=1885.16-9.76 X_{1}-4.422 X_{2}+6.967 X_{3}$ & -0.099 & 0.166 & -0.065 & 0.362 & 0.036 & 0.619 & - & - & 0.114 & 0.870 & 0.458 \\
\hline sDectin-1 $=0.204+0.000 X_{1}+0.000 X_{2}+0.001 X_{3}$ & 0.036 & 0.618 & -0.072 & 0.071 & 0.030 & $0.026^{*}$ & - & - & 0.087 & 0.504 & 0.680 \\
\hline sTAC $=0.847+0.003 X_{1}-0.001 X_{2}+0.005 X_{3}$ & 0.038 & 0.596 & -0.023 & 0.743 & 0.033 & 0.646 & - & - & 0.058 & 0.225 & 0.879 \\
\hline sTOS $=5.048-0.034 X_{1}+0.154 X_{2}+0.032 X_{3}$ & -0.024 & 0.738 & 0.155 & $0.030^{*}$ & 0.011 & 0.876 & - & - & 0.160 & 1.737 & 0.161 \\
\hline $\mathrm{sOSI}=0.029+0.000 X_{1}+0.093 X_{2}+0.0134 X_{3}$ & -0.090 & 0.208 & 0.044 & 0.533 & 0.002 & 0.975 & - & - & 0.103 & 0.714 & 0.545 \\
\hline
\end{tabular}

$X_{1}=$ age (years), $X_{2}=\mathrm{RCBG}(\mathrm{mg} / \mathrm{dl}), X_{3}=$ age of initiation of sexual activity (years), $X_{4}=$ duration of infection (years); beta regression coefficients: $\beta 1=$ age, $\beta 2=\mathrm{RCBG}, \beta_{3}=$ age of initiation of sexual activity, $\beta_{4}=$ duration of infection; $r=$ multiple correlation coefficient; ${ }^{*}$, ${ }^{*}$, and ${ }^{* * *}$ indicate significant at $p \leq 0.05, p \leq 0.01$, and $p \leq 0.001$ respectively 
correlations and regression pattern were observed between different measures of OS and two PRRs of the present study, suggesting the probable contribution of other host genes, defect in which may collectively be conferring risk of RVVI. The other reason for low OS observed in cases or unexpected correlation pattern might be the evasion strategies employed by pathogens. As for instance, Candida has strategies to neutralize and evade the oxidative stress by expressing superoxide dismutase (SODs) and other antioxidant enzymes on the cell surface. These extracellular SODs also have vital role in the detoxification of superoxide radicals generated by phagocytes; and hence prevent massive ROS accumulation (Frohner et al., 2009; Wellington et al., 2009). In addition, $C$. albicans catalase and vacuole (fungal organelle) formation has been suggested to counteract the oxidative stress (Palmer et al., 2005; Palmer, 2011). Also, co-culturing of macrophages with $C$. albicans cells lacking Sod4 and Sod5 has shown to lead to massive extracellular ROS accumulation in vitro (Frohner et al., 2009) . Thus, the analysis of the present study suggested reduced SMBL and oxidative stress measures along with high sDectin-1 levels, as a potential disease specifier for RVVI and its types.

Moreover, sTAC was found to be negatively correlated with age and age of initiation of sexual activity in RVVI, $\mathrm{BV}$, and VVC cases. Further indicating that, increase in age and age of initiation of sexual activity cause decrease in antioxidant strength in these cases. Also, TOS was found to be increased with age in VVC and decreased with age of initiation of sexual activity in MI. This finding of the present study is in agreement with the study that suggested increase in oxidative stress is age-related (Rowiński et al., 2013) and in contrast to the study where with increase in age, TOS, and TAC level decreased (Aslan et al., 2014). Further, different studies have evaluated the production of catalase, peroxide oxidase, tocopherol, some antioxidant vitamins, lipid peroxidation, protein, and DNA oxidation and found contradictory associations of these factors with age (Finkel \& Holbrook, 2000; Tanabe et al., 2002; MutluTürkoğlu et al., 2003; Huang \& Appel, 2003). In addition, a study showed no significant correlation of TAC with age of women (Kostka et al., 1998). Thus, there are no consistent perspectives about ageassociated change in antioxidant capacity, which may perhaps be due to the use of different measurement methods by different studies. Furthermore, sOSI was found to be significantly increased with duration of infection in BV, suggesting the constant generation of ROS, as a part of controlled inflammatory reaction against infections. Furthermore, in the present study, sMBL was found to be positively correlated with age of initiation of sexual activity in RVVI and its types, while
sDectin-1 showed negative significant correlation with the same in BV and VVC. Also the contradictory association of sDectin-1 was found with RCBG in BV and VVC. No significant correlation between sMBL and sDectin-1 was found with age. However, previous studies have showed negative correlation of sMBL with age that noticeably decreases after 40 years of age in healthy individuals, while no such association of sDectin-1 is reported till date (Ip et al., 2004; Vasconcelos \& Fonseca, 2011). To further complement these findings, the regression analysis also suggested the dependency of all the studied serum biomarkers on variables, i.e., age, RCBG, age of initiation of sexual activity, and duration of infection. This further suggests the importance to take into account the dependency of serum biomarkers on exogenous factors before considering these parameters as potential risk markers of RVVI.

\section{Conclusion}

In conclusion, both inflammation and oxidative stress stimulate each other and act together in providing defense against RVVI. Both processes are in such a tight link, that defect in one may lead to defect in other, contributing to the pathogenesis of RVVI. Therefore, recognition and treatment of primary anomaly is of great clinical importance to restore host homeostasis. As for instance, the primary source of defect identified in the present study is MBL, whose low expression leads to the defective collaboration between two studied PRRs further leading to defective ROS production with no observed protective oxidative stress, increasing susceptibility to RVVI. Therefore, substituting the required MBL in representative sample of Indian population may restore host homeostasis and provide recovery from RVVI, suggesting the recombinant MBL therapy as a novel therapeutic approach for RVVI (Keizer et al., 2014). However, before considering these parameters as potential risk markers of RVVI, information regarding their dependency on system factors is necessary. Such studies in larger datasets are needed to validate the medicinal possibilities of MBL for RVVI in different populations.

\footnotetext{
Acknowledgements

The authors express their sincere gratitude to University Grants Commission, New Delhi, Government of India for providing Senior Research Fellowship to NK.

\section{Authors' contributions}

NK reviewed the literature, was involved in the design, performing experiments, analysis, and interpretation, and drafted the manuscript. SS participated in sample collection and RWI diagnosis. MK, JS, and SS contributed to the experimental design, data analysis, manuscript editing, and supervision. All authors read and approved the final manuscript.
}

\section{Funding}

Not applicable 


\section{Availability of data and materials}

The data that support the findings of this study are available from the corresponding author upon reasonable request.

\section{Ethics approval and consent to participate}

The present study was commenced after getting approval from the Institutional Ethics Committee (approval no. 06/HG dated 02/01/2015) of Guru Nanak Dev University, Amritsar (Punjab), India, in accordance with Indian Council of Medical Research guidelines (ICMR, 2006) modified from Declaration of Helsinki (2004). Voluntary consent in written was attained from all the participants.

\section{Consent for publication}

All authors gave their consent for publication of this manuscript.

\section{Competing interests}

The authors declare they have no competing interests.

\section{Author details}

'Department of Molecular Biology and Biochemistry, Guru Nanak Dev University, Amritsar, Punjab, India. ${ }^{2}$ Department of Human Genetics, Guru Nanak Dev University, Amritsar, Punjab, India. ${ }^{3}$ Department of Obstetrics and Gynaecology, Bebe Nanki Mother and Child Care Centre, Government Medical College, Amritsar, Punjab, India.

Received: 23 April 2019 Accepted: 13 June 2019

\section{Published online: 10 July 2019}

\section{References}

Aslan R, Kutlu R, Civi S et al (2014) The correlation of the total antioxidant status (TAS), total oxidant status (TOS) and paraoxonase activity (PON1) with smoking. Clin Biochem. 47(6):393-397

Atashili J, Poole C, Ndumbe PM et al (2008) Bacterial vaginosis and HIV acquisition: a meta-analysis of published studies. AIDS. 22(12):1493

Aycicek A, Erel O, Kocyigit A (2005) Decreased total antioxidant capacity and increased oxidative stress in passive smoker infants and their mothers. Pediatr Int. 47(6):635-639

Babula O, Lazdane G, Kroica J et al (2003) Relation between recurrent vulvovaginal candidiasis, vaginal concentrations of mannose-binding lectin, and a mannose-binding lectin gene polymorphism in Latvian women. Clin Infect Dis. 37(5):733-737

Babula O, Lazdāne G, Kroica J et al (2005) Frequency of interleukin-4 (IL-4)-589 gene polymorphism and vaginal concentrations of IL-4, nitric oxide, and mannose-binding lectin in women with recurrent vulvovaginal candidiasis. Clin Infect Dis. 40(9):1258-1262

Birben E, Sahiner UM, Sackesen C et al (2012) Oxidative stress and antioxidant defense. World Allergy Organ J. 5(1):9

Bogavac M, Lakic N, Simin N et al (2012) Bacterial vaginosis and biomarkers of oxidative stress in amniotic fluid. J Matern Fetal Neonatal Med. 25(7):10501054

Bradford LL, Ravel J, Bruno V (2013) Understanding vulvovaginal candidiasis through a community genomics approach. Current Fungal Infection Reports. 7(2):126-131

Chen Z, Zhang Z, Zhang $\mathrm{H}$ et al (2015) Analysis of the oxidative stress status in nonspecific vaginitis and its role in vaginal epithelial cells apoptosis. BioMed Res Int. 2015

de Souza Bonfim-Mendonça P, Ratti BA, Godoy JD et al (2014) $\beta$-Glucan Induces Reactive Oxygen Species Production in Human Neutrophils to Improve the Killing of Candida albicans and Candida glabrata Isolates from Vulvovaginal Candidiasis. PLoS One. 9(9):e107805

Dundar Y, Aslan R (2000) Antioxidative stress. East J Med. 5(2):45-47

Durugbo II, Nyengidiki TK, Bassey G et al (2015) Bacterial vaginosis among women with tubal factor infertility in Nigeria. Int J Gynecol Obstet 131(2): $133-136$

Erel O (2004) A novel automated direct measurement method for total antioxidant capacity using a new generation, more stable ABTS radical cation. Clin Biochem. 37(4):277-285

Erel O (2005) A new automated colorimetric method for measuring total oxidant status. Clin Biochem. 38(12):1103-1111

Ferwerda B, Ferwerda G, Plantinga TS et al (2009) Human dectin-1 deficiency and mucocutaneous fungal infections. N Engl J Med. 361(18):1760-1767
Finkel T, Holbrook NJ (2000) Oxidants, oxidative stress and the biology of ageing. Nature. 408(6809):239

Förstermann U, Sessa WC (2011) Nitric oxide synthases: regulation and function. Eur Heart J. 33(7):829-837

Frasson AP, De Carli GA, Bonan CD et al (2012) Involvement of purinergic signaling on nitric oxide production by neutrophils stimulated with Trichomonas vaginalis. Purinergic Signalling. 8(1):1-9

Frohner IE, Bourgeois C, Yatsyk K et al (2009) Candida albicans cell surface superoxide dismutases degrade host-derived reactive oxygen species to escape innate immune surveillance. Mol Microbiol 71(1):240-252

Gadjeva M, Takahashi K, Thiel S (2004) Mannan-binding lectin—a soluble pattern recognition molecule. Mol Immunol. 41(2-3):113-121

Gantner BN, Simmons RM, Canavera SJ et al (2003) Collaborative induction of inflammatory responses by dectin-1 and Toll-like receptor 2. J Exp Med. 197(9):1107-1117

Ghazanfari M, Falahati M, Fattahi A et al (2017) Is MBL serum concentration a reliable predictor for recurrent vulvovaginal candidiasis? Mycoses.

Gonçalves B, Ferreira C, Alves CT et al (2016) Vulvovaginal candidiasis: Epidemiology, microbiology and risk factors. Crit Rev Microbiol 42(6):905-927

Gupta R, Sharma M, Lakshmy R et al (2009) Improved method of total antioxidant assay. Indian J Biochem Biophys. 46:126-129

Gupta S, Kunti S, Chatterjee S et al (2016) Oxidative stress index as a biochemical parameter in major depressive disorder. Asian J Med Sci 7(5):31-35 (E-ISSN 2091-0576; P-ISSN 2467-9100)

Halliwell B (1996) Antioxidants in human health and disease. Ann Rev Nutr 16(1): 33-50

Harma M, Harma M, Erel O (2005) Oxidative stress in women with preeclampsia. Am J Obstet Gynecol. 192(2):656-657

Hartshorn KL, Sastry K, White MR et al (1993) Human mannose-binding protein functions as an opsonin for influenza A viruses. J Clin Invest. 91(4):1414-1420

Henić E, Thiel S, Mårdh PA (2010) Mannan-binding lectin in women with a history of recurrent vulvovaginal candidiasis. Eur J Obstet Gynecol Reprod Biol. 148(2):163-165

Huang HY, Appel $\amalg$ (2003) Supplementation of diets with a-tocopherol reduces serum concentrations of $\gamma$-and $\delta$-tocopherol in humans. J Nutr. 133(10): 3137-3140

Ip WK, Lau YL (2004) Role of mannose-binding lectin in the innate defense against Candida albicans: enhancement of complement activation, but lack of opsonic function, in phagocytosis by human dendritic cells. J Infect Dis. 190(3):632-640

Ip WK, To YF, Cheng SK et al (2004) Serum mannose-binding lectin levels and $\mathrm{mbl} 2$ gene polymorphisms in different age and gender groups of southern Chinese adults. Scand I Immunol. 59(3):310-314

Johnson CJ, Kernien JF, Hoyer AR et al (2017) Mechanisms involved in the triggering of neutrophil extracellular traps (NETs) by Candida glabrata during planktonic and biofilm growth. Sci Rep. 7(1):13065

Jomova K, Vondrakova D, Lawson M et al (2010) Metals, oxidative stress and neurodegenerative disorders. Mol Cell Biochem. 345(1-2):91-104

Kalia N, Kaur M, Sharma S et al (2018) A Comprehensive in silico analysis of regulatory SNPs of human CLEC7A gene and its validation as genotypic and phenotypic disease marker in recurrent vulvovaginal infections. Front Cell Infect Microbiol. 8:65

Kalia N, Sharma A, Kaur M et al (2016) A comprehensive in silico analysis of nonsynonymous and regulatory SNPs of human MBL2 gene. Springerplus. 5(1):811

Kalia N, Singh J, Sharma S et al (2015) Prevalence of vulvovaginal infections and species specific distribution of vulvovaginal candidiasis in married women of north india. Int J Curr Microbiol App Sci. 4(8):253-266

Kalia N, Singh J, Sharma S et al (2017) Genetic and phenotypic screening of mannose-binding lectin in relation to risk of recurrent vulvovaginal infections in women of North India: a prospective cohort study. Front Microbiol. 8:75

Kalia N, Singh J, Sharma S, \& Kaur M (2019a) SNPs in 3'-UTR region of MBL2 increases susceptibility to recurrent vulvovaginal infections by altering sMBL levels. Immunobiology. 224(1):42-49

Kalia N, Singh J, Sharma S, \& Kaur M (2019b) Impact of SNPs interplay across the locus of MBL2, between MBL and Dectin-1 gene, on women's risk of developing recurrent vulvovaginal infections. Cell \& bioscience. 9(1):35

Kawasaki T, Ma Y, Uemura K et al (2000) Mannan-binding protein (MBP)dependent cell-mediated cytotoxicity (MDCC). Immunopharmacology. 1(49):85

Keizer MP, Wouters D, Schlapbach LJ et al (2014) Restoration of MBL-deficiency: redefining the safety, efficacy and viability of MBL-substitution therapy. Mol Immunol 61(2):174-184 
Kostka T, Drai J, Berthouze SE et al (1998) Physical activity, fitness and integrated antioxidant system in healthy active elderly women. Int J Sports Med. 19(07): 462-467

Li D, Dong B, Tong Z et al (2012b) MBL-mediated opsonophagocytosis of Candida albicans by human neutrophils is coupled with intracellular Dectin1-triggered ROS production. PLoS One. 7(12):e50589

Li J, McCormick J, Bocking A et al (2012a) Importance of vaginal microbes in reproductive health. Reprod Sci. 19(3):235-242

Lima-Junior DS, Mineo TW, Calich VL, et al. Dectin-1 activation during Leishmania amazonensis phagocytosis prompts Syk-dependent reactive oxygen species production to trigger inflammasome assembly and restriction of parasite replication. J Immunol 2017 Aug 7:ji1700258.

Liu F, Liao Q, Liu Z (2006) Mannose-binding lectin and vulvovaginal candidiasis. Int J Gynecol Obstet. 92(1):43-47

Lucas K, Maes M (2013) Role of the Toll like receptor (TLR) radical cycle in chronic inflammation: possible treatments targeting the TLR4 pathway. Mol Neurobiol 48(1):190-204

Lugrin J, Rosenblatt-Velin N, Parapanov R et al (2014) The role of oxidative stress during inflammatory processes. Biol Chem. 395(2):203-230

Malla N, Valadkhani Z, Harjai K et al (2004) Reactive nitrogen intermediates in experimental trichomoniasis induced with isolates from symptomatic and asymptomatic women. Parasitol Res. 94(2):101-105

Medzhitov R (2008) Origin and physiological roles of inflammation. Nature. 454(7203):428

Milanese M, Segat L, De Seta F et al (2008) MBL2 genetic screening in patients with recurrent vaginal infections. Am J Reprod Immunol. 59(2):146-151

Mulu W, Yimer M, Zenebe $Y$ et al (2015) Common causes of vaginal infections and antibiotic susceptibility of aerobic bacterial isolates in women of reproductive age attending at Felegehiwot referral Hospital, Ethiopia: a cross sectional study. BMC Women's Health. 15(1):42

Mutlu-Türkoğlu Ü, İlhan E, Öztezcan S et al (2003) Age-related increases in plasma malondialdehyde and protein carbonyl levels and lymphocyte DNA damage in elderly subjects. Clin Biochem 36(5):397-400

National Family Health Survey 2 (NFHS 2) 1998-99, India (1999) Mumbai: International Institute for Population Sciences (IIPS) and Macro International. 1999:307-14. Available from: https://www.dhsprogram.com/pubs/pdf/FRIND2/ FRIND2.pdf

Pacher P, Beckman JS, Liaudet L (2007) Nitric oxide and peroxynitrite in health and disease. Physiol Rev. 87(1):315-424

Palmer GE (2011) Vacuolar trafficking and Candida albicans pathogenesis. Commun Integr Biol. 4(2):240-242

Palmer GE, Kelly MN, Sturtevant JE (2005) The Candida albicans vacuole is required for differentiation and efficient macrophage killing. Eukaryotic Cell. 4(10):1677-1686

Pellis V, De Seta F, Crovella S et al (2005) Mannose binding lectin and C3 act as recognition molecules for infectious agents in the vagina. Clin Exp Immunol. 139(1):120-126

Poljsak B, Milisav I (2012) The neglected significance of "antioxidative stress". Oxidative Med Cell Longev. 2012

Powell AM, Nyirjesy P (2014) Recurrent vulvovaginitis. Best Pract Res Clin Obstet Gynaecol 28(7):967-976

Reiter RJ (1995) Oxidative processes and antioxidative defense mechanisms in the aging brain. FASEB J. 9(7):526-533

Rose S, Edwin B, Kannan I (2017) Bacterial vaginosis-a risk factor for preterm labour: a case-control study. Indian J Obstet Gynecol Res 4(4):381-383

Rowiński R, Kozakiewicz M, Kędziora-Kornatowska K et al (2013) Markers of oxidative stress and erythrocyte antioxidant enzyme activity in older men and women with differing physical activity. Experimental Gerontology. 48(11):1141-1146

Sharma RK, Pasqualotto FF, Nelson DR et al (1999) The reactive oxygen species - total antioxidant capacity score is a new measure of oxidative stress to predict male infertility. Human Reprod. 14(11):2801-2807

Sherrard J, Donders G, White D (2011) 2011 European (IUSTI/WHO) Guideline on the Management of Vaginal Discharge. Int J STD AIDS. 22(8):421-429

Shewade HD, Jeyashree K, Mahajan P et al (2017) National guidelines on screening for diabetes among patients with tuberculosis in India: Need for clarity and change in screening cut off? Diabetes Metab Syndr. 11:S929-S930

Somannavar S, Ganesan A, Deepa M et al (2009) Random capillary blood glucose cut points for diabetes and pre-diabetes derived from community-based opportunistic screening in India. Diabetes Care. 32(4):641-643
Svobodová E, Staib P, Losse J, et al. Differential interaction of the two related fungal species Candida albicans and Candida dubliniensis with human neutrophils. J Immunol. 2012 Jul 30:1200185.

Tanabe K, Masuda K, Sugawara J et al (2002) Effects of daily physical activity on oxidative stress in middle-aged and elderly people. Jpn J Phys Fitness Sports Med. 51(3):325-336

Underhill DM, Rossnagle E, Lowell CA et al (2005) Dectin-1 activates Syk tyrosine kinase in a dynamic subset of macrophages for reactive oxygen production. Blood. 106(7):2543-2550

Vasconcelos LR, Fonseca JP (2011) do Carmo RF, et al. Mannose-binding lectin serum levels in patients with leprosy are influenced by age and MBL2 genotypes. Int J Infect Dis. 15(8):e551-e557

Wellington M, Dolan K, Krysan DJ (2009) Live Candida albicans suppresses production of reactive oxygen species in phagocytes. Infect Immunity. 77(1): 405-413

Workowski KA, Bolan GA (2015) Sexually transmitted diseases treatment guidelines, 2015. MMWR. Recommendations and reports: morbidity and mortality weekly report. Recomm Rep. 64(RR-03):1

Yadav M, Dubey ML, Gupta I et al (2006) Nitric oxide radicals in leucocytes and vaginal washes of Trichomonas vaginalis-infected symptomatic and asymptomatic women. Parasitology. 132(3):339-343

\section{Publisher's Note}

Springer Nature remains neutral with regard to jurisdictional claims in published maps and institutional affiliations.

\section{Submit your manuscript to a SpringerOpen ${ }^{\circ}$ journal and benefit from:}

- Convenient online submission

- Rigorous peer review

- Open access: articles freely available online

High visibility within the field

- Retaining the copyright to your article

Submit your next manuscript at $>$ springeropen.com 